\title{
COMPUTATION OF PERIODIC MAGNETIC FIELD IN FERROMAGNETIC CONDUCTIVE MEDIUM AND SUPPLY CURRENT HARMONICS BY USING HARMONIC BALANCE FINITE ELEMENT METHOD
}

\author{
I.S. Petukhov, \\ Institute of Electrodynamics of National Academy of Sciences of Ukraine, \\ pr. Peremohy, 56, Kyiv, 03057, Ukraine. \\ E-mail: igor petu@mail.ru
}

The harmonic balance finite element method for two dimensional periodic magnetic field in a conductive ferromagnetic medium is formulated. To convert of partial differential equation system into the system of nonlinear algebraic equations the weak formulation of Galerkin method is used. Structural steel and silicon steel with different magnetic properties and various electrical conductivity are studied. It is described how to take into account the nonlinear properties of medium in mathematical model. The spectrum of supply current and flux density on the surface and inside the medium were computed provided the sinusoidal voltage fed. The dependencies of the amplitudes of high harmonics versus the steel properties and amplitude of the first harmonic of magnetic flux density at the surface of medium are presented. References 14, figures 5.

Key words: harmonic balance method, finite element method, ferromagnetic medium, magnetic field spectrum, current spectrum.

Introduction. Magnetic field simulation in ferromagnetic medium requires taking into account magnetic saturation and hysteresis phenomena. These phenomena cause occurrence of high harmonics in magnetic field, flux density and supply current. If it is necessary to study a periodic process of an electromagnetic device the simulation in the frequency domain is preferable to numerical integration in time-domain. Currently, the finite element method (FEM) mainly is used for modeling of magnetic field. In periodic process complex variable representing the only main harmonic is used. And in such case no spectra can be found. In $[7,8,9,13]$ it was shown that harmonic balance finite element method (HBFEM) is the most effective method under in this situation. Unlike the single-harmonic simulation, which uses magnetization curve for effective values, HBFEM uses real one and gives the instantaneous values of magnetic field and eddy currents in a period. Therefore this method allows to increase the accuracy of flux density and iron losses determining. The situation is rather complicated by the presence of eddy currents but HBFEM can be effectively used in this case too [12].

Apart from the computation of iron losses another important problem is evaluation of current supply spectrum due to nonlinear properties of medium. But it is not possible to calculate the current spectrum in voltage fed devices by using mono-harmonic approach. Computation of a transient is not preferable due to some known reasons [7]. HBFEM gives the spectrum directly $[3,14]$ and for that reason it is most suitable method which allows to find the stationary periodic solution. Aim of the article is to study influence of iron saturation and eddy current to spectrum of supply current by using HBFEM.

The simulation was carried out with GE2D package which supports the HBFEM for twodimensional low frequency electromagnetic problems. The package was developed in the Institute of electrodynamics of the NAS of Ukraine and used first order triangle finite elements [6]. This package was used earlier for computation of particle tracing in stationary magnetic field [1] and parameters of permanent magnet electrical machines [5].

Mathematic model. The model of nonlinear magnetic field in conductive immovable medium is based on partial differential equation in terms of vector magnetic potential $\boldsymbol{A}$

$$
\nabla \times \mathbf{f}(\nabla \times \mathbf{A})=-\gamma \nabla \varphi-\gamma \partial \mathbf{A} / \partial t+\mathbf{J},
$$

where $\boldsymbol{f}(\bullet)$ is nonlinear vector function representing dependence of field strength components $\left(H_{x}, H_{y}\right)$ vs magnetic flux density components $\left(B_{x}, B_{y}\right), \gamma$ is an electric conductivity, $\varphi$ is a scalar electric potential, $t$ is a time, $\boldsymbol{J}$ is an external exciting current density. The above-mentioned nonlinear function for isotropic medium is determined with the relationship

$$
\left(H_{x}, H_{y}\right)=H(B) /\|B\|\left(B_{x}, B_{y}\right),
$$

where $H(B)$ is an expression of the normal magnetization curve, $\|B\|$ is the Euclidean norm of the magnetic flux density vector.

Consider the case of a two-dimensional magnetic field which has the only spatial component $A=A_{z}$, provided that there are no external sources of electric potential $\varphi$ and external current $\boldsymbol{J}$ inside the medium. Taking into account above-mentioned, the equation (1) can be rewritten in the following form

\footnotetext{
(C) Petukhov I.S., 2017
} 


$$
\frac{\partial}{\partial x} H_{y}\left(\frac{\partial A}{\partial x}, \frac{\partial A}{\partial y}\right)-\frac{\partial}{\partial y} H_{x}\left(\frac{\partial A}{\partial x}, \frac{\partial A}{\partial y}\right)+\gamma \frac{\partial A}{\partial t}=0,
$$

where $x$ and $y$ are the axes of Cartesian coordinate system.

To study the influence of nonlinearity to wave form of the eddy currents and supply current respectively without influence of any geometry features it is enough to consider subdomain of rectangle, shown in Fig. 1. The subdomain is cut from the cross section of slab which is infinite in $x$ and $z$ directions. The alternating magnetic field is excited by the thin layer of current density $J_{w}$ located on the top and bottom surfaces of slab (Fig. 1). Thanks to symmetry relative to the horizontal axis the only one half of cross section may be examined. If the magnetic field is excited by a voltage source then the magnetic flux $\Phi$ along $x$ - direction inside the slab may be represented according to Stoke's theorem as

$$
\Phi=\int_{S} B_{x} d \boldsymbol{S}=\oint_{l} A d \boldsymbol{l}
$$

Consequently the voltage $\Delta U$ applied to selected part of winding of width $b$ is given by expression

$$
\Delta u=\Delta w \frac{l}{b} \frac{d}{d t} \int_{b} A(t) d x
$$

where $\Delta w$ is a number of turns, $l$ is a reference length. Due to that the vector potential does not depend on $x$

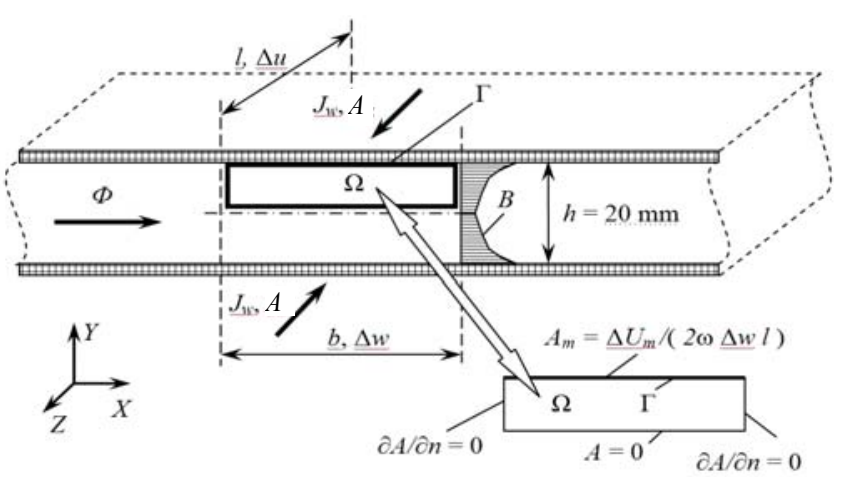

Fig. 1 coordinate, the relationship between voltage and amplitude sine vector potential $A_{\Gamma}$ on the slab surface may be found from (5) as

$$
\Delta u(t)=2 \omega \Delta w l A_{m} \sin (\omega t),
$$

where $\omega$ is an angular frequency. Thus the boundary condition on the slab surface (Fig. 1) is

$$
A_{\Gamma}=\Delta U_{m} \sin (\omega t) /(2 \omega \Delta w l),
$$

where $\Delta U_{m}$ is an amplitude of sine supply voltage.

According to harmonic balance method the approximate solution of vector potential $\tilde{A}(x, y, t)$ and other variables are represented by trigonometric polynomials like this

$$
\tilde{A}(x, y, t)=\sum_{i=1}^{n} \sum_{g=1}^{n_{g}}\left[A_{c v i} \cos (v \omega t)+A_{s v i} \sin (v \omega t)\right] N_{i}(x, y),
$$

where $n$ - number of nodes of mesh; $n_{g}$ - number of harmonic base function; $v=\lceil g / 2\rceil ; N_{i}$ is node base function of element. As mentioned above, triangular first order finite elements have been used. In accordance with HBFEM we should find all node variables, namely, flux density, field strength and current as truncated Fourier series containing the same number of harmonics like (8). Thus, discrete analog of derivatives for determination of flux density components in (3) is

$\tilde{B}_{x}(\alpha)=\frac{\partial \tilde{A}}{\partial y}=\sum_{h=1}^{n_{g}} \sum_{j=j_{1}}^{j_{3}} A_{j h} \xi_{h}(\alpha) \frac{\partial N_{j}}{\partial y} ; \quad \tilde{B}_{y}(\alpha)=-\frac{\partial \tilde{A}}{\partial x}=-\sum_{h=1}^{n_{g}} \sum_{j=j_{1}}^{j_{3}} A_{j h} \xi_{h}(\alpha) \frac{\partial N_{j}}{\partial x}$,

where $j_{1}-j_{3}$ is number of element nodes, $\xi_{g}(\alpha)$ is a trigonometric base function: $\cos (v \omega t)$ or $\sin (v \omega t)$ in $(8)$.

Application of Galerkin method in weak formulation gives integral relationship

$$
\begin{gathered}
-\frac{2}{\pi} \int_{0}^{\pi} \int_{\Omega}\left[\tilde{H}_{y} \frac{\partial N_{i}}{\partial x}-\tilde{H}_{x} \frac{\partial N_{i}}{\partial y}\right] \xi_{g}(\alpha) d \Omega d \alpha+\frac{2}{\pi} \int_{0}^{\pi} \int_{\Gamma} \tilde{H}_{\tau} N_{i} \xi_{g}(\alpha) d \Omega d \alpha+ \\
+\frac{2}{\pi} \int_{0}^{\pi} \int_{\Omega} \gamma \omega \frac{\partial \tilde{A}}{\partial \alpha} N_{i} \xi_{g}(\alpha) d \Omega d \alpha=0
\end{gathered}
$$

where $H_{\tau}$ is unknown surface field strength. Assuming that the magnetic field outside the infinite slab is zero (like outside a solenoid) one can say that the surface field strength $H_{\tau}$ is equal to surface current density of excitation winding $J_{w}$. As the result, the algebraic equation system of FEM includes two unknown vectors. The first one is a vector of harmonic amplitudes of potential $\boldsymbol{A}_{\Omega \mathrm{g}}$, in nodes, which do not belong to surface of slab. The second one is amplitudes of harmonics of supply current density $\boldsymbol{J}_{g}$, in nodes belonging to the surface (top boundary of the selected rectangle on Fig. 1). Let the period be divided into $L$ equal intervals. Then 
for a node with the index $i(i=1 \ldots n)$ belonging to the element $e$ and for a harmonic base function with the index $h\left(h=1 \ldots n_{g}\right)$ of a contribution $R_{i h}^{\mathrm{e}}$ to the residual vector $\boldsymbol{R}$ gives

$$
\begin{gathered}
R_{i h}^{e}=\frac{1}{L} \int_{e}\left\{-\sum_{s=1}^{L}\left[\tilde{H}_{y} \frac{\partial N_{i}}{\partial x}-\tilde{H}_{x} \frac{\partial N_{i}}{\partial y}\right] \xi_{h}\left(\alpha_{s}\right)+\right. \\
\left.+\gamma \omega \sum_{j=j_{1}, j_{2}, j_{3}}\left[(\mp v) A_{j, h \pm 1} \xi_{h}\left(\alpha_{s}\right) N_{j}\right] \xi_{h}\left(\alpha_{s}\right) N_{i}\right\} d S_{e}+\frac{1}{L} \int_{\Gamma^{e}} \sum_{s=1}^{L} J_{h} \xi_{h}\left(\alpha_{s}\right) d \Gamma^{e},
\end{gathered}
$$

where $j_{1}, j_{2}, j_{3}$ are nodes of element $e, S_{e}$ is the square of element, $\left(\alpha_{s}=2 \pi(s-1) / L ; s=1 \ldots L\right)$ are the nodes in time domain; $\Gamma^{\mathrm{e}}$ is the part of the boundary belonging to element $e$. The major step in the formulation of a nonlinear system of equation is to get expressions for Jacobi matrix obtaining from (11). This way, by using of through indexes $k=n_{g}(i-1)+h$ and $n=n_{g}(j-1)+g$, we have contribution of finite element $e$ to $k, n$-cell of global matrix

$$
\begin{gathered}
J_{k n}^{e}=\frac{1}{L} \int_{e}\left(-\sum_{s=1}^{L}\left[\frac{\partial H_{y}}{\partial A_{n}} \frac{\partial N_{i}}{\partial x}-\frac{\partial H_{x}}{\partial A_{n}} \frac{\partial N_{i}}{\partial y}\right] \xi_{h}\left(\alpha_{s}\right)+\right. \\
\left.+\left[\gamma \omega(\mp v) \xi_{h}^{2}\left(\alpha_{s}\right) N_{i} N_{j}\right]\right) d S_{e}+\frac{1}{L} \int_{\Gamma^{e}} \sum_{s=1}^{L} \xi_{h}\left(\alpha_{s}\right) d \Gamma^{e},
\end{gathered}
$$

where $H_{x}, H_{y}$ are nodal instantaneous values of field strength. Derivatives in the first term of (12) may be written as

$$
\frac{\partial H_{y}}{\partial A_{n}}=\frac{\partial H_{y}}{\partial B_{y}} \frac{\partial B_{y}}{\partial A_{n}}+\frac{\partial H_{y}}{\partial B_{x}} \frac{\partial B_{x}}{\partial A_{n}} ; \quad \frac{\partial H_{x}}{\partial A_{n}}=\frac{\partial H_{x}}{\partial B_{y}} \frac{\partial B_{y}}{\partial A_{n}}+\frac{\partial H_{x}}{\partial B_{x}} \frac{\partial B_{x}}{\partial A_{n}},
$$

in turn, the derivatives from field strength components $\partial H_{\eta} / \partial B_{\eta},(\eta=x, y)$ are defined from the vector function (2) but derivatives $\partial B_{\eta} / \partial A_{n}$ in accordance to (9) are determined by

$$
\frac{\partial B_{y}}{\partial A_{n}}=-\xi_{h}\left(\alpha_{s}\right) \frac{\partial N_{j}}{\partial x} ; \quad \frac{\partial B_{x}}{\partial A_{n}}=\xi_{h}\left(\alpha_{s}\right) \frac{\partial N_{j}}{\partial y} .
$$

In order to study the influence of magnetic properties of steel monotone Frohlich function for approximation of relative magnetic permeability was used

$$
\mu=1+\mu_{m x} /\left[1+\left(\|\mathbf{B}\| / B_{s}\right)^{m}\right]
$$

where $\mu_{m x}$ is initial magnetic permeability, $B_{s}$ is magnetic flux density, corresponding to the inflection point (half saturation), $m$ is a factor of function steepness.

Two steel compositions were studied, namely, low silicon (structural steel, $\mu_{m x}=1000 ; B_{s}=1,44 ; m$ $\left.=6,0 ; \gamma=7,14 \cdot 10^{6} \mathrm{~S} \cdot \mathrm{m}^{-1}\right)$ and silicon steel $\left(\mu_{m x}=5000 ; B_{s}=1,15 \mathrm{~T} ; m=10, \gamma=2,3 \cdot 10^{6} \mathrm{~S} \cdot \mathrm{m}^{-1}\right)$. The correspondence between approximating dependencies and catalog data is shown in Fig. 2.

If indexing of all nodes starts from the nodes

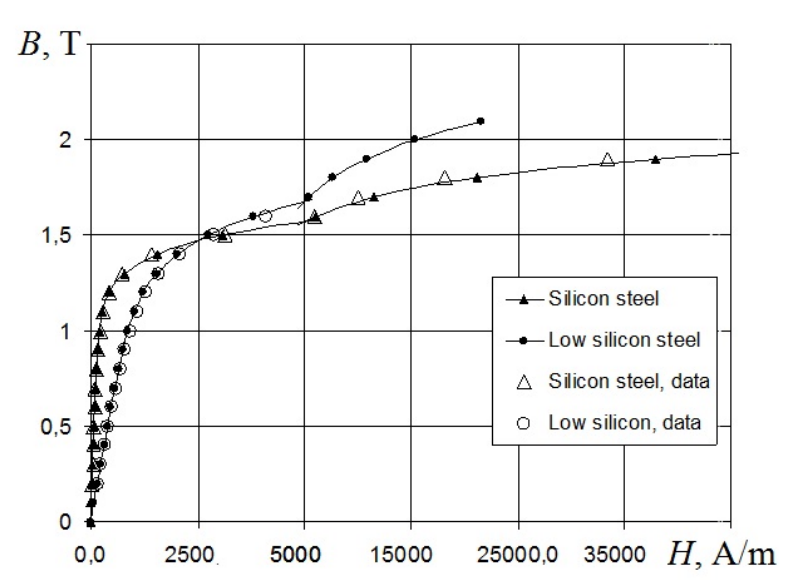

Fig. 2 belonging to top edge of domain, the system equation can be represented in general matrix form as

$$
\left[\begin{array}{cc}
{[1]} & Z \\
H & G
\end{array}\right]\left\{\begin{array}{c}
\mathbf{J}_{g} \\
\mathbf{A}_{\Omega}
\end{array}\right\}=\left\{\begin{array}{c}
\mathbf{A}_{\Gamma} \\
0
\end{array}\right\},
$$

where boundary values of $\boldsymbol{A}_{\Gamma}$ are defined from (7).

For solving the nonlinear system (16) the modified Newton's method [10] which includes original optimization algorithm and gives quick and reliable convergence $[4,6]$ is used in GE2D package. The reliability of convergence is provided by the monotone approximation of magnetic permeability too. To increase the efficiency of computation the algorithm used the reception proposed in [11], comprising converting of expression for magnetic permeability (15) to dependence of specific conductance on magnetic flux density squared $v\left(B^{2}\right)$.

Results and discussion. The dependence of supply current spectrum versus value of applied voltage has been studied. As more suitable criterion of process intensity the first harmonic amplitude of flux density in the surface can be adopted. It is caused by the fact that voltage or flux depends on the size of slab, but the flux 

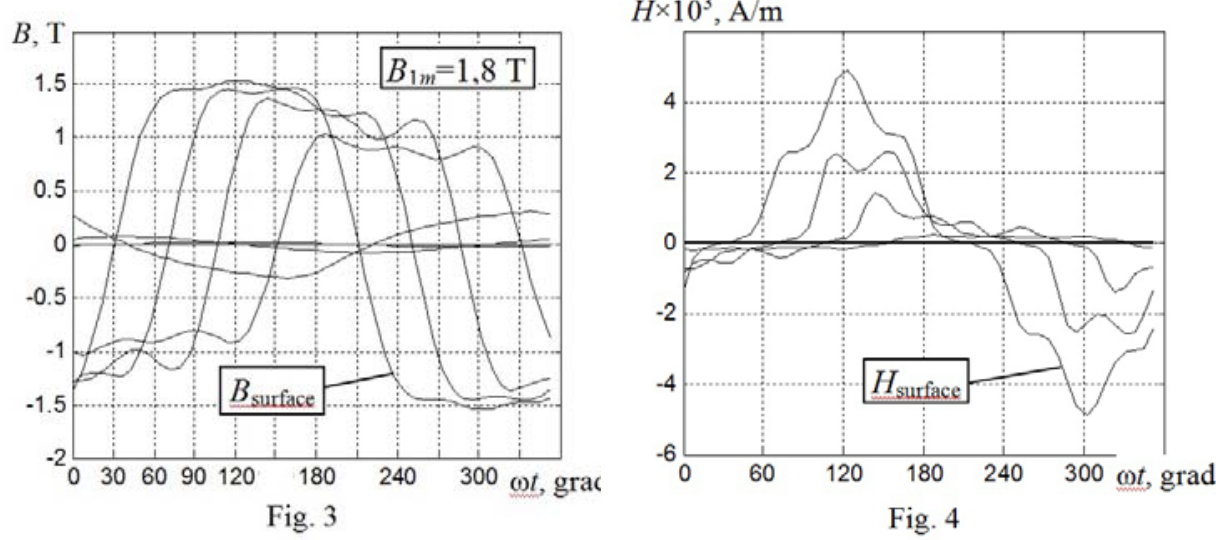

density does not. Skin effect leads to non sinusoidal waveform of flux density both on the surface and inside the metal. This fact, provided that the amplitude of main flux density harmonic $B_{1 m}$ equals to $1,8 \mathrm{~T}$, is confirmed by time dependencies shown in Fig. 3 and Fig. 4 for flux density and field strength respectively in ten slices along the depth of metal. The modeling was car-

ried out taking into account three first odd harmonics $(1,3,5)$. As preliminary numerical experiments have proved, the maximum harmonic number of 5 is enough to ensure the accuracy of both losses and amplitudes calculation [4]. The current waveform has therefore some peaks (Fig. 4). On the contrary, the waveforms of flux density are more flat than sinusoid. It is necessary to note, that in spite of non sinusoidal flux density character the flux and the voltage are sinusoidal as stated in problem formulation. The reason of this is phase variation of magnetic field along the depth.

The solution of system (16) gives spectra of supply current density $\boldsymbol{J}_{\mathrm{g}}$. Curves in Fig. 5 display a relationship between amplitude of main harmonic of the flux density and relative amplitudes of 3rd and 5th current harmonics (with respect to the amplitude of its first harmonic), where $\mu$ represents the maximum (initial) magnetic permeability, contained in formula (15). For comparison in Fig. 5 curves corresponding to non conductive medium are represented, marked with $\gamma=0$. This case corresponds to laminated magnetic core which has been studied in some publications [5,7].

As one can see, provided that the amplitude of fundamental harmonic of flux density is up to $2 \mathrm{~T}$, the amplitude of its third harmonic reaches $8 \ldots 18 \%$. And the higher specific resistance of steel or the more sharp bending of the magnetization curve (steepness of magnetic permeability curve (15) at II $\boldsymbol{B}$ II $=B_{s}$ ) is, the more significant is contribution of high harmonics. Thus the maximum part of high harmonics, more then $50 \%$, is observed in laminated magnetic core. The experimental data for amplitude of high harmonics in magnetization current arising in laminated core of real transformer is described in [2]. For third harmonic under condition that the amplitude of flux density $B_{m}$ corres-ponds to $1 ; 1,4 ; 2 \mathrm{~T}$, corresponding relative amplitude of third harmonic reaches $21 ; 27,5$ and $69 \%$ respectively. The results presented above have no good correlation with respect to obtained curves. It can be justified by the fact that ideal infinite object was considered. To uphold the obtained result it may be noted, that represented investigation was carried out not taking into account resistance of winding, flux leakage, external circuit parameters and other factors taking place in real transformers or inductors. With respect to the charts presented in Fig. 5 one may observe that the growth of amplitudes of current harmonics decreases with increasing of flux density. This feature may be explained by the increasing of linear part of magnetization curve in saturation region as magnetic flux density grows.

Conclusion. The spectrum of higher harmonics of supply current generated by nonlinear medium is significantly influenced by eddy currents therein. Laminated core causes maximal amplitude of the harmonics contained in supply current. Conversely, solid magnetic core causes lower amplitude of the high harmonics.

In addition in a case of solid magnetic core waveform of flux density on the surface is considerably flattened and significantly differs from a sinusoid. This fact should be taken into account when designing the devices indicating flux density in the surface of solid ferromagnet.

To obtain a high accuracy computation of current and flux density amplitudes, losses etc. it is enough to take into account the first five time harmonics of the field. If only three

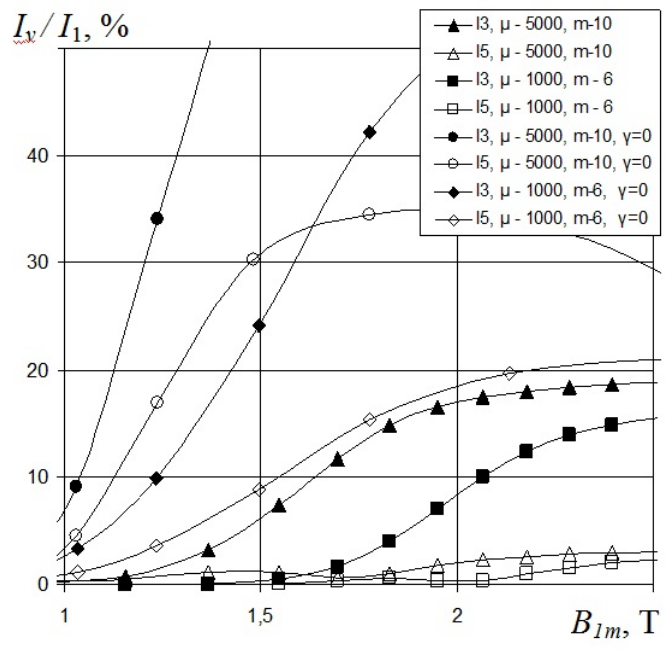

Fig. 5 
first odd harmonics exist the size of FEM matrix increases only three times compared to mono-harmonic simulation.

1. Antonov A.E., Petukhov I.S. Identification of the magnetic field of the rotor of a two-axis electrical machine // Tekhnichna Elektrodynamika. - No 1. - 1999. - Pp. 64-68. (Rus)

2. Bruskin D.E., Zorokhovich A.E., Khvostov V.S. Electrical machines. - Moskva: Vysshaia shkola, 1987. - 319 p. (Rus)

3. Cherepin V.T., Olykhovskiy V.L., Petukhov I.S. Optimizing the deflecting magnetic system of the mass spectrometer type of spheretron // Tekhnichna Elektrodynamika. - 1997. - No 4. - Pp. 3-7. (Rus)

4. Development of the methods for symmetrization and calculating the parameters of linear induction machines (Parameter - 7): 2002 year / Report: № State registration 0198U007472; National academy of science of Ukraine, Institute of electrodynamics. - Kiyv: Institute of Electrodynamics, 2002. - 105 p.

5. Gyselinck J., Dular P., Geuzaine C., Legros W. Harmonic-Balance Finite-Element Modeling of Electromagnetic Devices: A Novel Approach // IEEE Trans. on Magnetics. - 2002. - Vol. 38. - No 2. - Pp. 521-524.

6. Lu J., Yamada S., Harrison B. Application of Harmonic Balance-Finite Element Method (HBFEM) in the Design of Switching Power Supplies // IEEE Transactions on Power Electronics. - 1996. - Vol. 11. - No 2. - Pp. 347-355.

7. Lu J., Zhao X., Yamada S. Harmonic Balance Finite Element Method: Applications in Nonlinear Electromagnetics and Power Systems. - Wiley-IEEE Press, 2016. - 304 p.

8. Petukhov I.S. Simulation of alternating electromagnetic field in a conducting ferromagnetic medium by finite element method // Tekhnichna Elektrodynamika. - 2008. - No 4. - Pp. 18-26. (Rus)

9. Petukhov I.S. Simulation of alternating electromagnetic field in a conducting ferromagnetic medium // Pratsi Instytutu Elektrodynamiky Natsionalnoi Akademii nauk Ukrainy. - 2004. - No 2(8). - Pp. 15-16. (Rus)

10. Reklaitis G.V., Ravindran A., Ragsdell K.M. Engineering Optimization: Methods and Applications. - New York: Wiley, 1983.$667 \mathrm{p}$.

11. Silvester P.P., Ferrary R.L. Finite Elements for Electrical Engineers. - Cambridge: Cambridge University press, 1983. -494 p.

12. Stefan Ausserhofer, Biro O., Preis K. An Efficient Harmonic Balance Method for Nonlinear Eddy-Current Problems // IEEE Trans. on Magnetics. - 2007. - Vol. 43. - No 4. - Pp. 1229-1232.

13. Zhao X., Li L., Lu J., Cheng Z., Lu T., Huang H., Liu G. An Efficient Fixed-Point Harmonic-Balanced Method Taking Account of Hysteresis Effect Based on the Consuming Function // ICCP Proceedings. - 2010. - Pp. 179-181.

14. Yamada S., Bessho K. Harmonic field calculation by the combination of finite element analysis and harmonic balance method // IEEE Trans. on Magnetics. - 1988. - Vol. 24. - No 6. - Pp. 2588-2590.

\section{УДК 621.3 .01}

РОЗРАХУНОК ПЕРІОДИЧНОГО МАГНІТНОГО ПОЛЯ У ФЕРОМАГНІТНОМУ ЕЛЕКТРО-ПРОВІДНОМУ СЕРЕДОВИЩІ ТА ГАРМОНІК У СТРУМІ ЖИВЛЕННЯ МЕТОДОМ ГАРМОНІЧНОГО БАЛАНСУ СУМІСНО 3 МЕТОДОМ СКІНЧЕННИХ ЕЛЕМЕНТІВ

I.C. Пєтухов, докт.техн.наук

Інститут електродинаміки НАН України,

пр. Перемоги, 56, Київ, 03057, Україна.

E-mail: igor petu@mail.ru

Представлено метод гармонічного балансу сумісно з методом скінченних елементів для двовимірного магнітного поля в електропровідному феромагнітному середовищі. Для перетворення диференціального рівняння в часткових похідних до системи нелінійних алгебрайчних рівнянь використовувався метод Гальоркіна в слабкому формулюванні. Досліджувалися конструкиійна та легована сталь із різними магнітними властивостями та різною електропровідністю. Описано врахування нелінійних властивостей у математичній моделі. Розраховано спектри струму живлення та магнітної індукції на поверхні та всередині середовища за умов живлення синусоїдальною напругою. Представлено залежності амплітуд вищих гармонік від властивостей сталі та амплітуди першої гармоніки магнітної індукиї на поверхні середовища. Бібл. 14, рис. 5.

Ключові слова: метод гармонічного балансу, метод скінченних елементів, феромагнітне середовище, спектр магнітного поля, спектр струму.

УДК 621.3 .01

РАСЧЕТ ПЕРИОДИЧЕСКОГО МАГНИТНОГО ПОЛЯ В ФЕРРОМАГНИТНОЙ ПРОВОДЯЩЕЙ

СРЕДЕ И ГАРМОНИК ПИТАЮЩЕГО ТОКА МЕТОДОМ ГАРМОНИЧЕСКОГО БАЛАНСА

СОВМЕСТНО С МЕТОДОМ КОНЕЧНЫХ ЭЛЕМЕНТОВ

И.С. Петухов, докт.техн.наук

Институт электродинамики Национальной академии наук Украины,

пр. Победы, 56, Киев, 03057, Украина. $\quad$ E-mail: igor petu@mail.ru

Сформулирован метод гармонического баланса совместно с методом конечных элементов для двумерного магнитного поля 6 электропроводящей ферромагнитной среде. Для преобразования дифференциального уравнения в частных производных в систему нелинейных алгебраических уравнений использовался метод Галеркина в слабой формулировке. Исследовались конструкционная и легированная сталь с различными магнитными свойствами и различной электропроводностью. Описан учет нелинейных свойств в математической модели. Рассчитаны спектры тока питания и магнитной индукиии на поверхности и внутри среды при условиях питания синусоидальным напряжением. Представлены зависимости амплитуд высших гармоник от свойств стали и амплитуды первой гармоники магнитной индукции на поверхности среды. Библ. 14, рис. 5.

Ключевые слова: метод гармонического баланса, метод конечных элементов, ферромагнитная среда, спектр магнитного поля, спектр токов. 